\title{
Interaction Design Research Of Suitable For Student Travel APP
}

\author{
Wen Ming Liu ${ }^{1, \mathrm{a}}$, Pei Lei Zhang*2,b \\ ${ }^{1}$ Shenyang Jianzhu University Shenyang China \\ ${ }^{2}$ Shenyang Jianzhu University Shenyang China
}

\begin{abstract}
In recent years, with the use of mobile phone APPs, more and more people like to use tourism APPs when traveling, and the tourism industry also enters a new era of wireless tourism. College students are a huge tourist group. This paper will summarize an APP suitable for students' tourism through the analysis of tourism APPs and tourist groups. This APP will make travel plans based on the student's time, including travel time, travel residence, travel strategy, travel expenses, tour groups, etc. It also includes working with schools and local police to keep students safe. There should be such an APP for student travel to make it convenient for students to travel, enrich their university experience, and make student travel safer and more convenient.
\end{abstract}

\section{Analysis on the development status of tourism APP}

With the continuous development of China's tourism industry and the advent of the Internet era, tourism APPs have developed rapidly. At present, there are common problems in the design of tourism APPs: The crowd scope is wide, the commercial advertisement inserts too much, the strategy recommendation is not true and so on. But each travel APP has its own features, These features enhance the user experience. Here are a few examples of the features of the travel APP:

\subsection{Luvtravel}

Luvtravel: This APP is comprehensive, covering transportation, tickets, food and accommodation. The special function in Luvtravel is to ask for a road card, which can translate place names into local languages, making it more convenient for customers to use them.

\subsection{Qunar.com}

Qunar.com: This APP provides users with information about air tickets, tickets and group purchases. The feature of this software is to systematically provide a tourist attractions surrounding services, according to the introduction of the APP, travel friends can play around the general understanding.

\subsection{SkyScanner}

SkyScanner: The most prominent feature is to be able to query low - price air tickets. It compares fares and alerts when fares are dropping.
Through the above examples, it is not difficult to find that each APP has its own unique functions, attracts customers with its own characteristics, gives customers a better travel experience, and becomes a good travel assistant.

\section{User analysis of student groups}

\subsection{Security issues}

With the improvement of life quality, college life is increasingly diversified, and college students have more time after class. More and more college students like to use their spare time and holidays to travel, or to go out for research according to the needs of the course. At the same time, with the increase of the number of students traveling, the safety problem of students traveling has become increasingly prominent, which may lead to the situation that college students lose contact with their parents and friends, or their property is stolen. Therefore, the safety of college students should be paid more attention to.

\subsection{How to attract students to use APP}

College students have strong learning ability, strong curiosity about external things, and high frequency of using mobile APP. Therefore, college students have always been a typical group of mobile APP users. Although college students have a strong ability to accept APPs, it can be seen from the preliminary survey that there are many tourism APPs in the market nowadays, and all of them have their own theme features, which also attract some students to use them. In this case, we need to think about how to attract students to use the tourism APP we developed. Therefore, in the design of this APP, we set APP service crowd to college students, the crowd narrow, we can according to the characteristics of college students 
designed a suitable for their APP, attract university students are willing to use our APP.

\subsection{Survey on students' consumption ability}

Questionnaire survey is the main research method used in the research on the consumption ability of students.

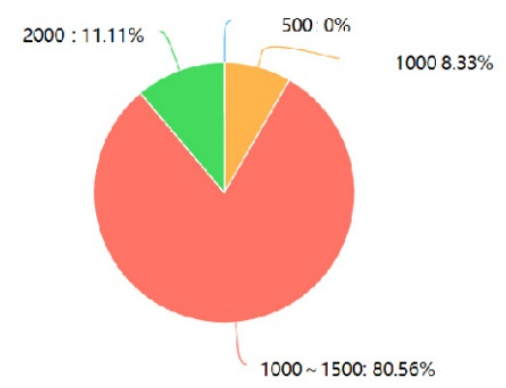

Figure 1. The majority of college students live on 1000-1500 yuan per month.

According to the results of the questionnaire survey, it can be seen that most college students' monthly living expenses range is $1000-1500$ yuan. So, we need to reduce the consumption cost of college students in the process of tourism. At the same time, due to the limited cost of living, the number of trips for college students is also limited, which requires us to recommend more suitable travel destinations for the students, and to be more realistic when screening tourists to provide travel strategies.

\section{App Design Strategy}

Through a comprehensive analysis of the development status of tourism APPs and the analysis of college students, we decided to design an APP for college students. The following is the analysis of the APP design.

\subsection{Solutions to safety problems}

Safety is the most worrying issue for parents when students travel. If a student loses contact with his or her parents during the trip, the parents cannot locate the student in time, and the police will delay the search time. To solve this problem, set up a function in the APP -binding. When students go to travel, and parents in the APP binding set in the position, so that parents don't need a moment to talk to their children, student's location information, real-time appeared long mobile phone at home, so when students lost parents can real-time report the location of the police students, or to provide students with the police finally lost in position, provide convenience for the police search task, greatly shorten the search time.

\subsection{Coping methods to attract students to use APP}

According to the research, the APP service group is finally set as college students, so that how to attract college students to use the APP has become a very important problem. There are two things that attract the most attention in the APP. One is the visual experience. The second is the key features of the APP. On the one hand, color is usually the first factor in terms of vision. Here we are targeted at the crowd is college students, so in terms of color selection, to choose some youthful color; Our APP is for tourism. From the perspective of tourism, the first thing we think of is green mountains, clear waters, blue sky and white clouds, so the basic color of the APP is set as blue, with red as the auxiliary color. Blue is a color that is widely accepted by the public. At the same time, many people believe that blue can bring people a sense of security and connect with nature, which also echoes the theme of our APP. The typesetting of words and pictures in the APP is also very important. Since our target group is college students, we should design according to the aesthetic requirements of college students for the typesetting of words and pictures. It can be seen from the products designed for students on the market that nowadays college students generally like simple products. Therefore, simple and clear typesetting is our positioning for typesetting of APP. On the other hand, it is the prominent functions of the APP. There are three key functions: security, money saving and convenience.

\subsection{Countermeasures to students' consumption problem}

As the main source of income for college students is their parents' regular living expenses, they have not yet realized their economic independence, and it is found through the survey that most of the students' living expenses are 10001500 yuan, so we should also pay more attention to how to save money. In order to save money, added a single this function. Students from various universities can connect with each other through the APP, and for students who want to go to a unified destination, the APP can launch a bid, which can be used to buy tickets and hotels at group price.

Through the analysis of the above three problems and propose solutions, the basic direction of the APP is determined.

\section{Overview of Qingtu APP design and APP framework}

Nowadays, travel should become more and more intelligent, with various travel apps and websites emerging in an endless stream. However, there is no targeted group, and after investigation, it is found that students are a very special group with a large number of tourists, so I decide to design a software for student tourism. Because the APP is aimed at students, the APP is named Qingtu App, which means the journey of young people. 


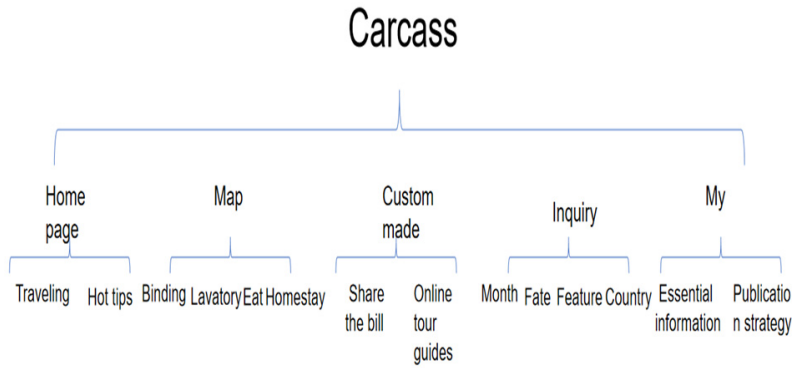

Figure 2. Basic framework of Qingtu APP

As you can see from the above diagram, the basic architecture of an APP has five aspects. They are home page, map, customization, query and mine. Through the distribution of these five aspects, the functions of the APP and the distribution of each function are determined.

\section{Qingtu APP functional design characteristics}

As a tourism APP, the functions of tourism sharing and popular strategies are essential. These functions can allow travel friends to publish their own travel feelings and make comments on the tourist destinations, so that the later travel friends can learn from them. The design features of the green road are mainly for the special situation of students to make adjustments, the following introduces the characteristics of each function.

\subsection{Map - Binding}

Security has always been an important issue in student travel, so the function of binding has been added. Qingtu can relate the location of students and parents, although parents can know the exact location of students when the mobile phone is turned off, adding a layer of protection for travel safety. A problem many people face when they travel is that they get separated. Although some apps have location functions, users must click to agree, and there is no way to contact someone if they don't see the phone. Therefore, in Qingtu the associated travel friends can also be automatically linked to the back, so that one party wants to find the other party is very convenient, and it can also let the travel friends always pay attention to the location of the fellow when playing.

\subsection{Map -- Toilet}

When traveling, it is difficult for everyone to find a toilet. This function is a small but convenient design point for travelers. There is a page that looks for the exact location of the toilet and displays the distance.

\subsection{Custom - spell list}

The initial design idea is to reduce the economic pressure of students, and at the same time enable college students to meet like-minded friends in the process of traveling.
Some college students choose to travel alone because they do not have the same hobbies. This kind of students can save money with the use of single-order, and greatly increase the safety of travel. For students who can use the APP, they need to $\log$ in the college information and personal identification information to ensure security.

\subsection{Customization -- online tour guide}

It is a very important demand to go out for a tour guide. In a strange city, a tour guide can help you plan the most suitable tour route for your time and needs, and introduce some historical sites in detail. But now the price of tour guide is more expensive, there is a lot of pressure for students. Therefore, an online tour guide is set up here. An online tour guide can be a student in a tourist city who needs to register a travel certificate. This on the one hand is convenient for students to travel, but also let some students have part-time jobs. Online guides have a review mechanism, and the better the reviews, the more orders they receive.

\section{Qingtu APP page design}

In the function and design of Qingtu development interface, the function segmentation should be reasonably arranged, and the basic needs of customers can be fulfilled at the same time. At that time, customers can experience efficiency and convenience when using the APP. In the page design, we should make full use of the principles of design and aesthetics to improve the visual effect in the APP, and try to fit the customers' daily habits of using mobile phones in the layout, so that customers can adapt to the APP in a quick time.

The design concept of Qingtu App: Qingtu is a travel APP. As the name implies, users will walk a lot when using it. Therefore, both Qing and Tu have an extension in the font design, representing the distance of the journey and the expectation for the future journey. The blue circle picture is taken as the background. On the one hand, the circle represents the earth and represents the wide range of travel involved in Qingtu APP. On the other hand, blue is a color yearning for freedom, and represents the sky and nature, which can give users a sense of security and make it easier for customers to accept.

In the design of Qingtu APP, the main interface design is to be simple and clear, and the color collocation should be harmonious, with blue as the main color and red as the secondary color. An important prerequisite for users to accept an APP is to have a good visual experience. In the interface design, on the one hand, we should maintain the consistency of the overall interface; on the other hand, we should also make the interface have diversity and outstanding characteristics. Consistency refers to the overall page style, the overall use of color matching consistent. Diversity refers to a consistent page style with outstanding features. In the process of continuous use by customers, the page can bring changes in visual elements through changes in functions, which can attract the attention of users. 


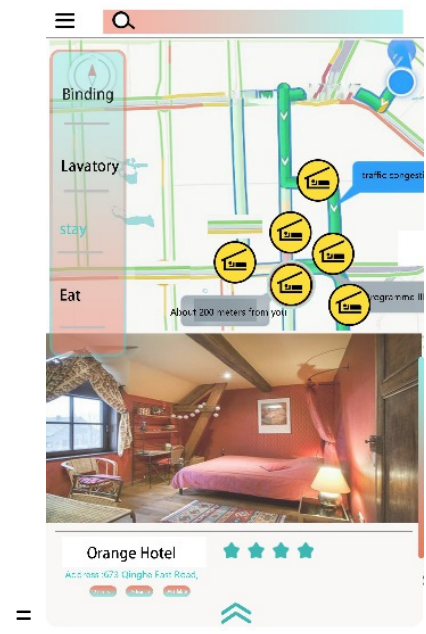

Figure 3. Qingtu Applogo design

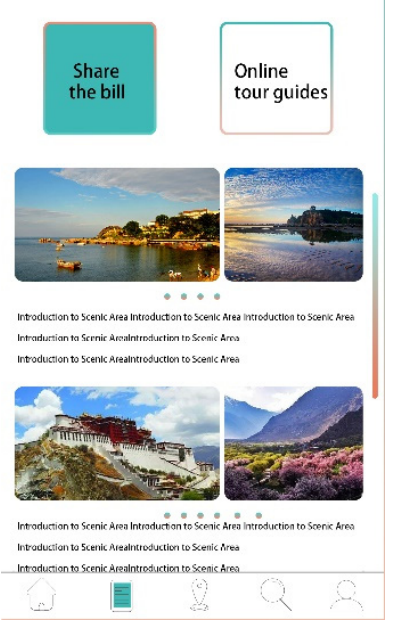

Figure 4. Qingtu APP page design display

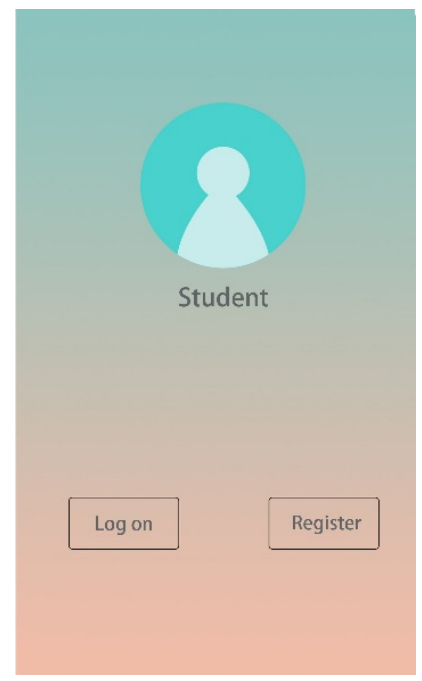

Figure 5. Qingtu APP login display

Figure 6. Qingtu APP map location page display

\section{7 conclusion}

By analyzing the development of tourism APP and student groups, this paper proposes and solves problems, thus designing this Qingtu APP. In this detailed description of the development process of QingTu APP, comprehensive, multi-level proposed the problems faced by college students travel, and put forward various solutions. In the face of specific groups, put forward specific important functions, so that students can step out of the school gate and go to the world with limited funds; Safety issues as a key issue, so that parents more assured that students travel.

\section{References}

1. Lan Pan. User Customized Intelligent Tourism APP Interface Design [J]. Information and Computers(Theoretical Edition), 2019(11): 110-111.

2. Junjie Zhou. User Engagement in the Context of Social Commerce: The Indirect Influence and Moderating Effect of User Interaction [J]. Management Review, 2015 (7) : 127-136.

3. Xiaoyan Wang, Guangwen Kong. Research on College Students' Consumer Behavior Oriented to Ecommerce Platforms [J]. Theater House, 2018(15).

4. Zhao Wang, Xin Li, Jian Zou. Research on the Influencing Factors of Promoting College Students' Online Consumption [J]. Science and Technology of light industry, 2018(4). 